\title{
Migration of a covered metallic stent following endoscopic ultrasound-guided hepaticogastros- tomy: fatal complication
}

Endoscopic retrograde access to the biliary tree is not always possible and endoscopic ultrasound (EUA)-guided biliary drainage is increasingly used. EUS-guided hepaticogastrostomy has been proved to be feasible, although safety issues still need to be evaluated. There are few reports [1-5] with $90 \%-100 \%$ technical and $75 \%-100 \%$ clinical success rates. Major complications included stent migration, bile leaks, and cholangitis $[4,5]$.

An 81-year-old man with obstructive jaundice secondary to gallbladder adenocarcinoma and duodenal stricture was referred for endoscopic drainage. Magnetic resonance imaging (MRI) showed an infiltrative mass and biliary stenosis with dilated intrahepatic ducts ( $\bullet$ Fig. 1).

The duodenal stricture was dilated with a balloon. Following failure of several attempts at transpapillary deep cannulation of the bile duct, a decision was taken to carry out transgastric EUS-guided drainage. A linear EUS scope positioned in the gastric lesser curvature disclosed a dilated intrahepatic biliary system ( $\bullet$ Fig. 2a), and a 19-gauge needle was inserted inside a left intrahepatic branch ( $\bullet$ Fig. 2 b). After stylet removal, a cholangiogram was obtained ( $\bullet$ Fig. 3 ) and a 0.035 -inch guide wire was introduced through the needle (॰ Video 1).

The guide wire was then positioned into an intrahepatic biliary branch. The transmural tract was enlarged by using a needle-knife. A partially covered self-expandable metal stent (SEMS), $10 \times 60 \mathrm{~mm}$ in size (Wallstent, Boston Scientific International, La Garenne Colombes, France), was inserted ( $\bullet$ Fig. 4).

At the end of the procedure, an enteral SEMS, $30 \times 90 \mathrm{~mm}$ in size (Wallflex, Boston Scientific), was placed across the duodenal stenosis ( $\bullet$ Fig. 5 and $\bullet$ Video $\mathbf{1}$ ).

\section{Video 1}

Endoscopic ultrasound showing the dilated intrahepatic biliary system and puncture with a 19-gauge needle. Cholangiogram at fluoroscopy and a 0.035 -inch guide wire positioned into an intrahepatic biliary branch after failed attempt to pass it through the stricture. Finally, deployment of a partially coated self-expanding metallic stent.

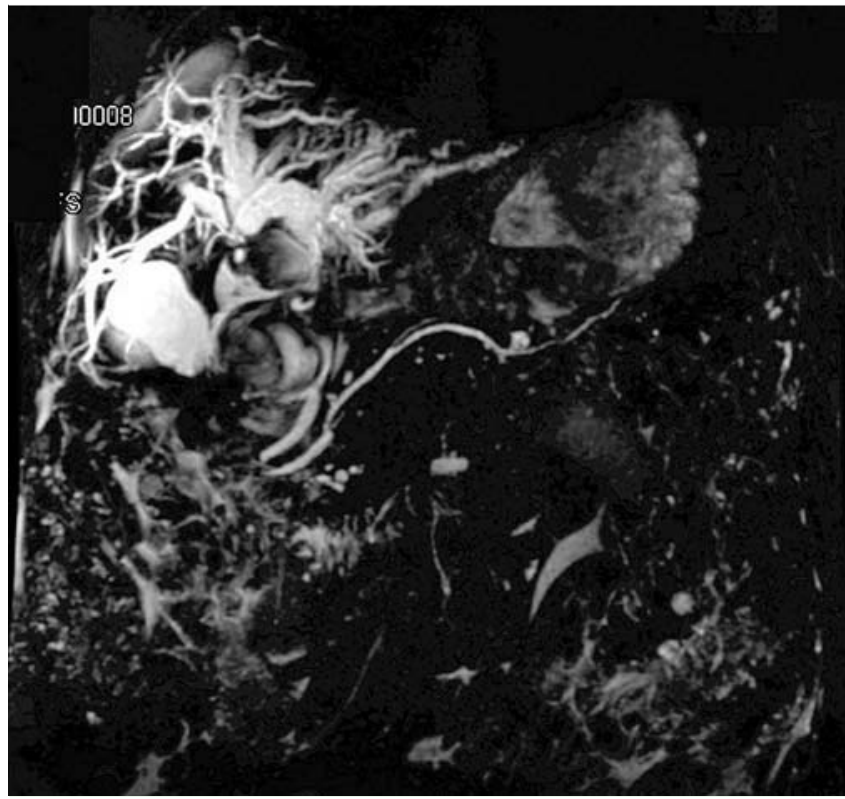

Fig. 1 Magnetic resonance imaging (MRI) showing a complex hilar stricture with dilated intrahepatic biliary tree.
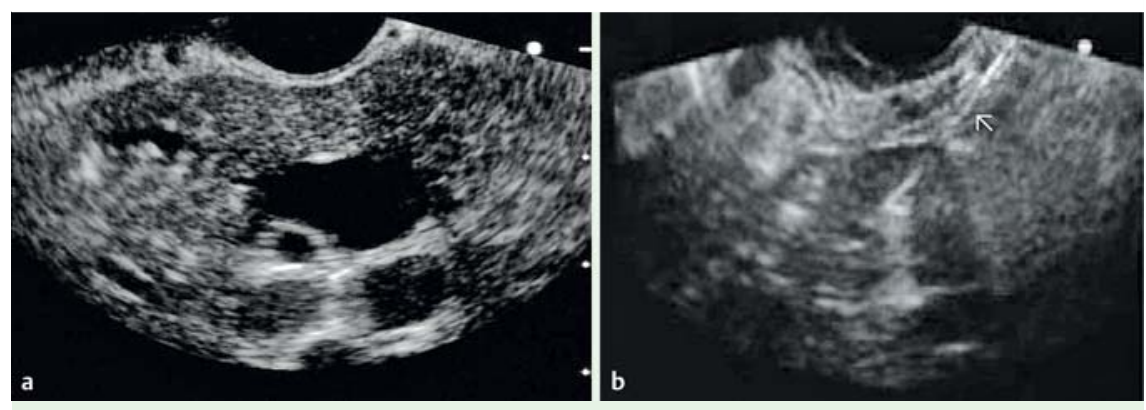

Fig. 2 a Endoscopic ultrasound (EUS) showing dilated left intrahepatic ducts. b Puncture of a left intrahepatic biliary branch under EUS guidance (arrow).

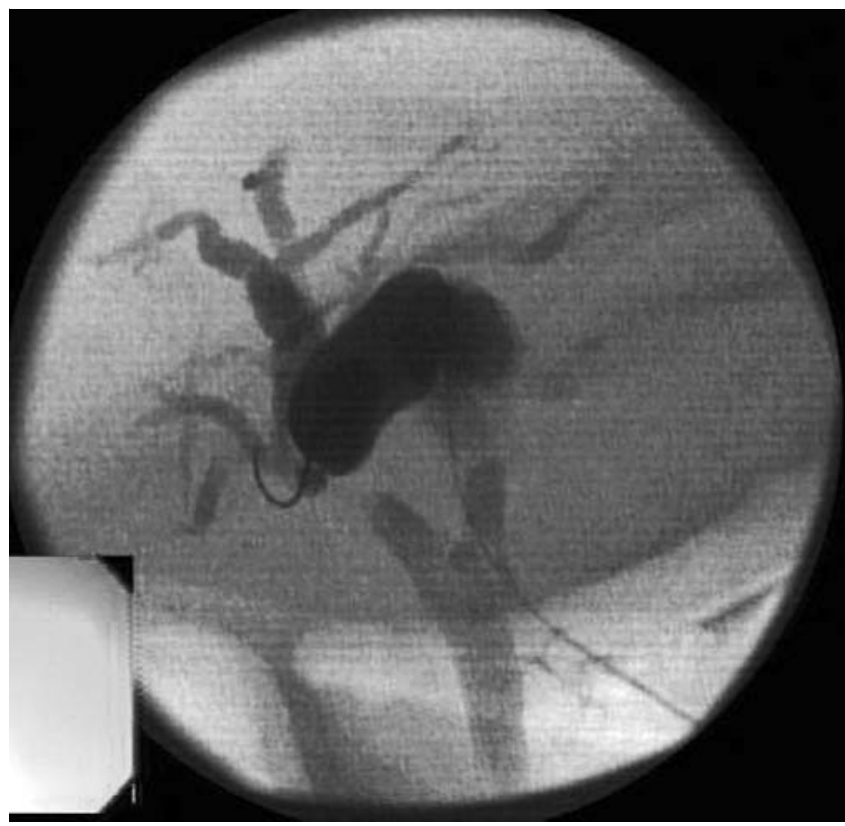

Fig. 3 Cholangiogram obtained after contrast injection through the endoscopic ultrasound needle, revealing dilated intrahepatic bile ducts and hilar stenosis. 

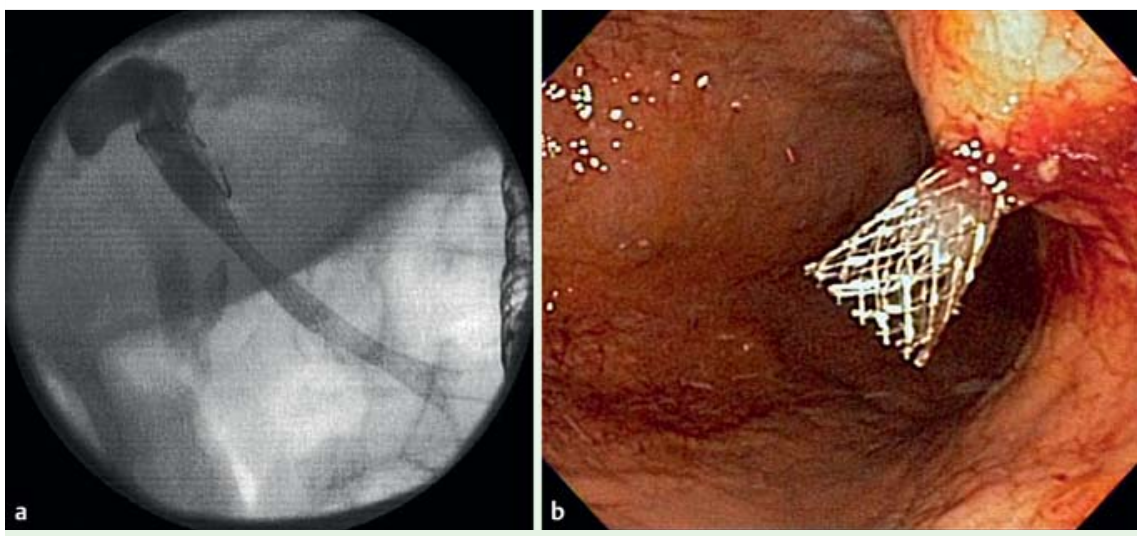

Fig. 4 a Fluoroscopic view of the covered self-expanding metallic stent after complete deployment. b Endoscopic view of the proximal end of the metallic stent through the gastric wall immediately after deployment.
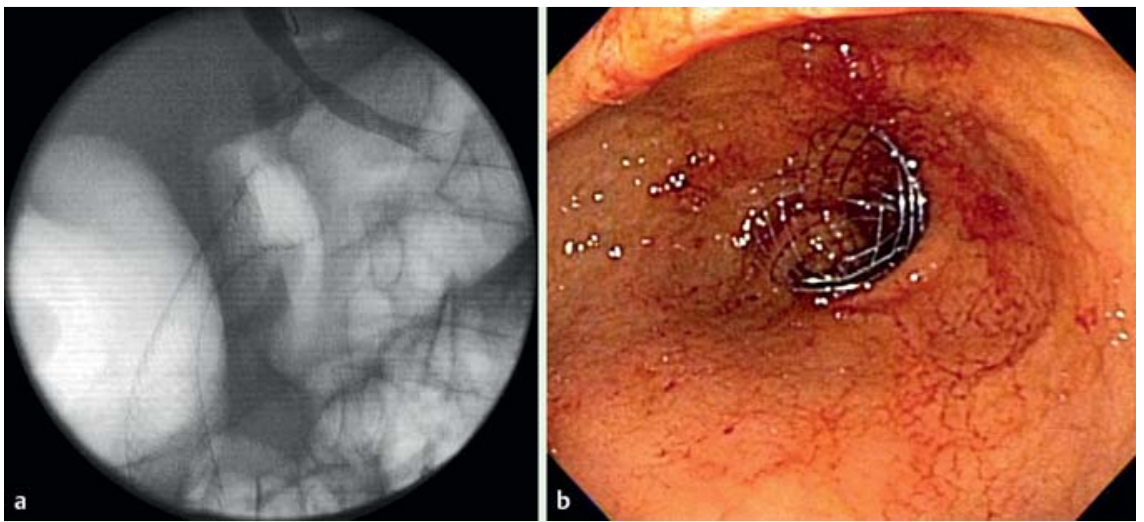

Fig. 5 a Fluoroscopic view of the enteral stent fully deployed across the duodenal stricture. b Endoscopic view of the proximal end of the stent.

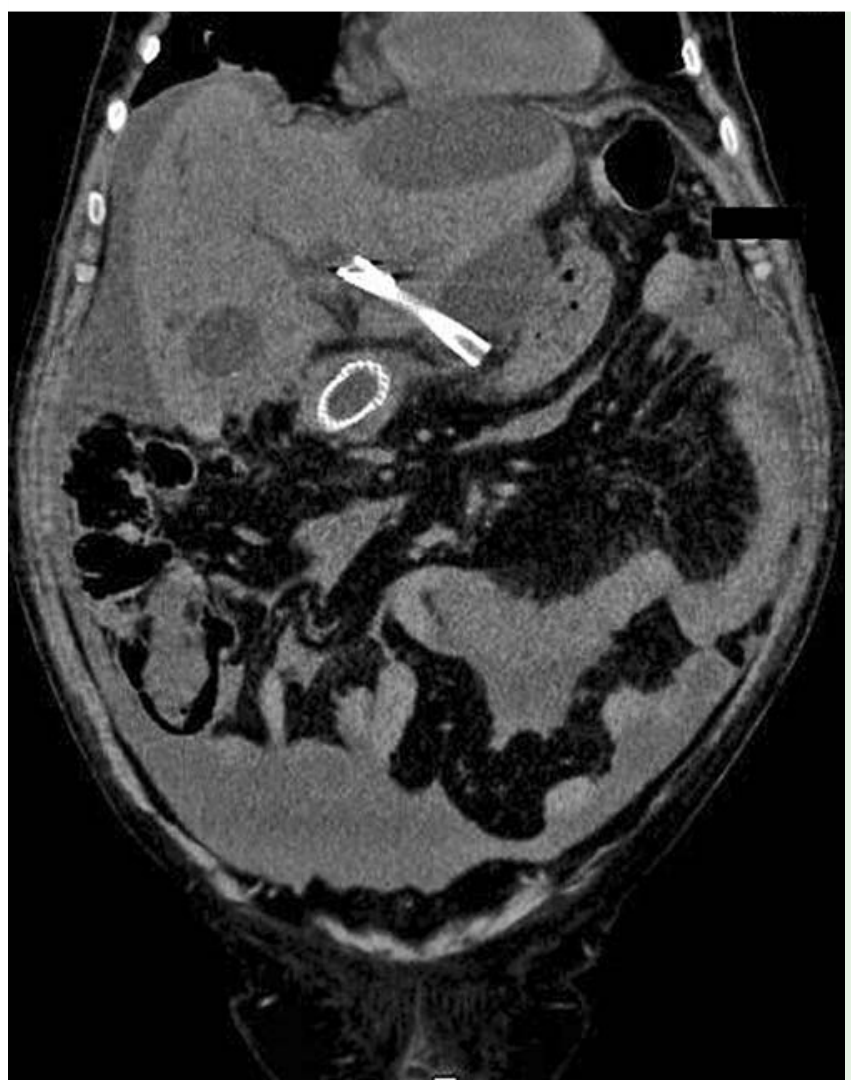

The procedure was technically successful and the patient was discharged. After 5 days, the patient presented again with abdominal pain and fever. CT scan revealed stent migration with its proximal end located within a large biloma ( $\mathbf{F i g} \mathbf{6}$ ).

Unfortunately, the patient's clinical status deteriorated because of sepsis and he died.

EUS-guided hepaticogastrostomy is a promising alternative in patients with failed drainage at endoscopic retrograde cholangiography. Further research is needed to address the associated safety issues, including the optimal stent to be used.

Endoscopy_UCTN_Code_CPL_1AL_2AD

\section{F. P. Martins, L. G. B. Rossini, A. P. Ferrari} Hospital Israelita Albert Einstein,

São Paulo, Brazil

\section{References}

1 Burmester E, Niehaus J, Leineweber $T$ et al. EUS-cholangio-drainage of the bile duct: report of 4 cases. Gastrointest Endosc 2003; 57: $246-251$

2 Giovannini M, Dotti M, Bories E et al. Hepaticogastrostomy by echoendoscopy as a palliative treatment in a patient with metastatic biliary obstruction. Endoscopy 2003; 35: 1076-1078

3 Artifon EL, Chaves DM, Ishioka S et al. Echoguided hepatico-gastrostomy: a case report. Clinics 2007; 62: 799-802

4 Will U, Thieme A, Fueldner F et al. Treatment of biliary obstruction in selected patients by endoscopic ultrasonography (EUS)-guided transluminal biliary drainage. Endoscopy 2007; 39: 292 - 295

5 Bories E, Pesenti C, Caillol F et al. Transgastric endoscopic ultrasonography-guided biliary drainage: results of a pilot study. Endoscopy 2007; 39: 287-291

Bibliography

DOI $10.1055 / \mathrm{s}-0029-1243911$

Endoscopy 2010; 42: E126 -E127

(c) Georg Thieme Verlag KG Stuttgart · New York . ISSN 0013-726X

Corresponding author

\section{F. P. Martins}

Alameda Ministro Rocha Azevedo

976 apt 71

CEP 01410-002

São Paulo

Brazil

fernandaprata@terra.com.br 